\title{
The Fabrication of Composite Material Based on Natural Macromolecules: A Review
}

\author{
Rony Mia $^{1^{*}}$ (1), Imon Biswas Shuva², Md. Abdullah Al Mamun², Md. Abu Bakar², \\ Md. Faridul Islam Rumman ${ }^{3}$, Md. Moshiur Rahman'
}

\begin{abstract}
${ }^{1}$ Hubei Key Laboratory of Biomass Fibers and Eco-Dyeing \& Finishing, College of Chemistry and Chemical Engineering, Wuhan Textile University, Wuhan, China

${ }^{2}$ State Key Laboratory of New Textile Materials and Advanced Processing Technologies, School of Textile Science \& Engineering, Wuhan Textile University, Wuhan, China

${ }^{3}$ State Key Laboratory of New Textile Materials, School of Technical Research \& Engineering, Wuhan Textile University, Wuhan, China

${ }^{4}$ Deperatment of Fashion Design \& Technology, Chattogram BGMEA Institute of Fashion \& Technology, Chattogram, Bangladesh Email: ^mroni_mia@yahoo.com, mroni_mia@niter.edu.bd
\end{abstract}

How to cite this paper: Mia, R., Shuva, I.B., Al Mamun, A., Bakar, A., Rumman, F.I. and Rahman, M. (2020) The Fabrication of Composite Material Based on Natural Macromolecules: A Review. Open Access Library Journal, 7: e6977.

https://doi.org/10.4236/oalib.1106977

Received: November 11, 2020

Accepted: December 6, 2020

Published: December 9, 2020

Copyright $\odot 2020$ by author(s) and Open Access Library Inc.

This work is licensed under the Creative Commons Attribution International License (CC BY 4.0).

http://creativecommons.org/licenses/by/4.0/

\begin{abstract}
The consciousness of environmental \& ecological impact has attained great attention for the preparation of new material \& various end-used applications. Macromolecules synthesized from natural resources have increased compared to synthetic resources in recent years. The fabrication of composite materials has another concept for increasing the durable properties of composite materials. This review paper focused on the fabrication of composite materials based on some natural sources macromolecules. Different types of macromolecules present in different fiber used in various fabrication. Here, wood, silk \& wool based macromolecules are described, where wood was from plant sources and silk \& wool was animal sources. The data cover the application of these natural macromolecules for the fabrication of composite materials. This review concludes that the fabrication of composite materials is one of the emerging areas in polymer science that gain attention for use in various applications.
\end{abstract}

\section{Subject Areas \\ Composite Material}

\section{Keywords}

Fabrication, Composite Material, Natural Macromolecules 


\section{Introduction}

Natural macromolecules enriched resources are rapidly emerging as sustainable, cost-effective and environmental-friendly fabrication of composite materials [1] [2]. Due to the concerns about environmental \& sustainable issues, natural macromolecules based fabrication of composite materials has attracted the attention of researchers, manufacturers and end users. These composite materials can be easily disposed of at the end of their use or at any time without harming the environment, which is not possible for synthetic macromolecules [3] [4].

Macromolecules are formed by the polymerization of small molecules called "monomer". It is also known as a polymer [5] [6] [7] [8]. Different types of macromolecules are available such as biological macromolecules, natural macromolecules, synthetic macromolecules etc. The purpose of macromolecules is varied from its sources $\&$ types like biological macromolecules used by the body to carry out various life activities [9] [10].

Nowadays, the use of the fabrication of composite materials has increased rapidly and replaced the traditional one. It is seen that natural macromolecules based composites have expanded their usages due to the advantages offered by these materials, i.e. biodegradability, high strength, low weight, high durability and low maintenance cost [11] [12]. Different composite materials are fabricated by the natural macromolecules such as cellulose, hemi-cellulose, proteins, lignin, pectin, starch, alginate, chitin, albumin etc. The sources are varied from one to another based on the collection \& end uses [13] [14].

The natural macromolecules from wood, silk or wool have good durable, ecological or environmental advantages. Among various composite materials, the fabrication of composite from natural macromolecules is primarily used as low cost materials that have functional structural properties. By taking advantages, natural macromolecules are now used on a large scale. This review article describes the recent research work based on natural macromolecules and their uses in fabrication of composite materials. Mainly the article focused the wood, silk \& wool based fabrication of composite materials. Herein, the summarization of preparation of natural macromolecules based composite materials is described. The different application is also shown for different purposes.

\section{Natural Components}

\subsection{Natural Fiber}

The classification of natural fiber is based on their origin such as plants, animals or minerals [15] [16] [17]. All plants fiber consists of cellulosic materials \& it includes various divisions, viz. seed fiber (cotton), leaf fiber (sisal, pineapple), bast fiber (flax, ramie), fruit fiber (coir), stalk fiber (rice) and other grass fiber [18] [19]. The animal fiber consists of animal hair \& silk fiber. The mineral fiber consists of asbestos [20]. A diagram with a various fibers is shown in Figure 1. Over the last few years, a number of researchers have been involved in studying in exploitation of natural fibers as composite materials [21]. 


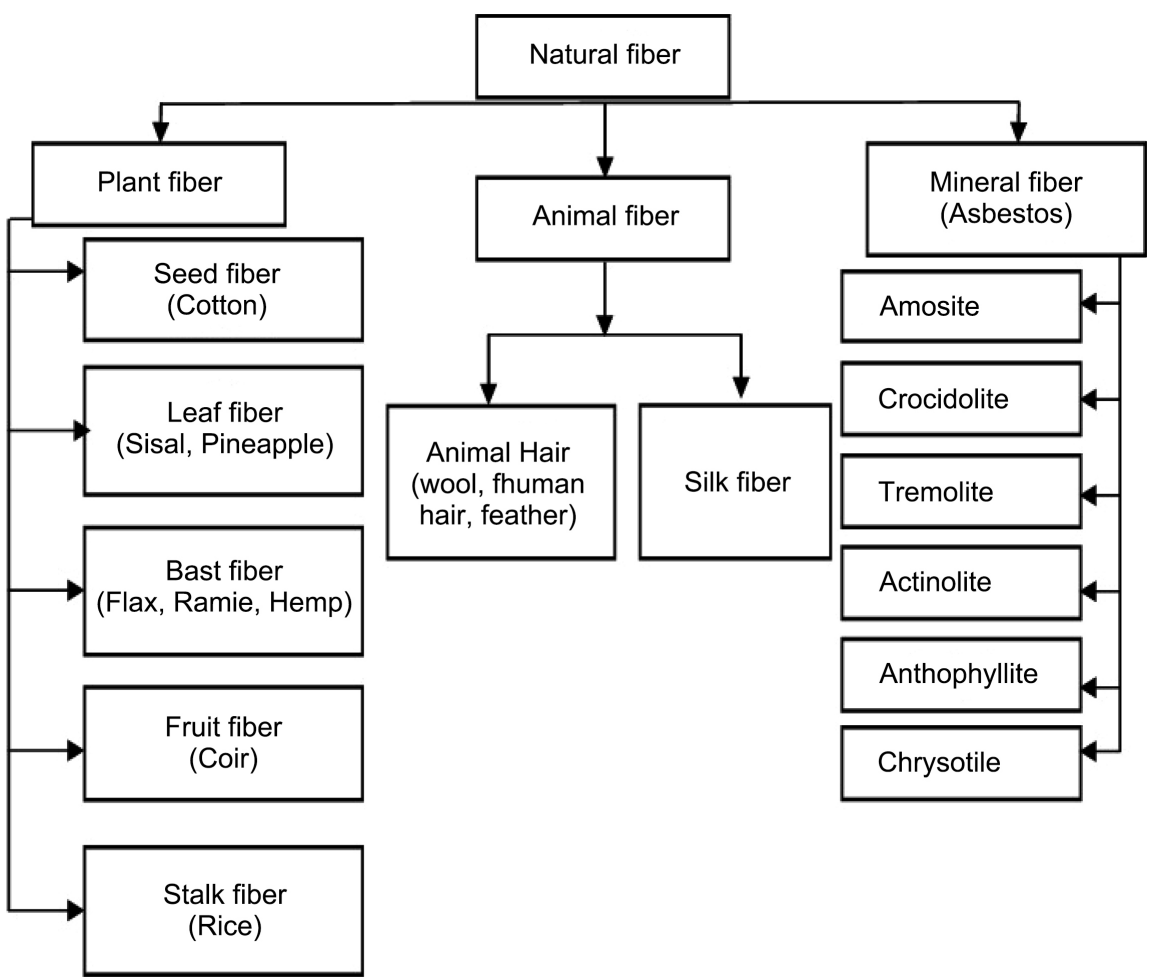

Figure 1. Classification of natural fibers.

\subsection{Natural Macromolecules}

The macromolecules are classified in different categories based on their application, use \& properties. From these classifications, natural macromolecules have attained great attention in recent years because of their environment sustainability \& biodegradability [22]. Natural macromolecules are classified based on the sources of natural fiber polymers. The macromolecules contain cellulose, hemi-cellulose, lignin, pectin, starch, alginate, chitin, albumin etc. The details classification is shown in Figure 2.

\section{Fabrication of Composite Materials}

\subsection{Wood Based Fabrication of Composite Materials}

In recent years, tremendous efforts have been dedicated to developing wood-derived fabrication of composite materials due to their distinctive properties, including environmental friendliness, renewability, and biodegradability. Thus, the uniqueness of the main components in natural macromolecules wood (cellulose and lignin) has attracted enormous interest for both fundamental research and practical applications [23]. Different macromolecular engineering emphasize the different precise design of well-defined polymers. The structures \& compositions are essential for the assembly into different morphologies which depends on the cellulose \& lignin to their derivatives. A wide range of wood derived materials have been presented with the application range from nano- to macromolecular is in Figure 3. 


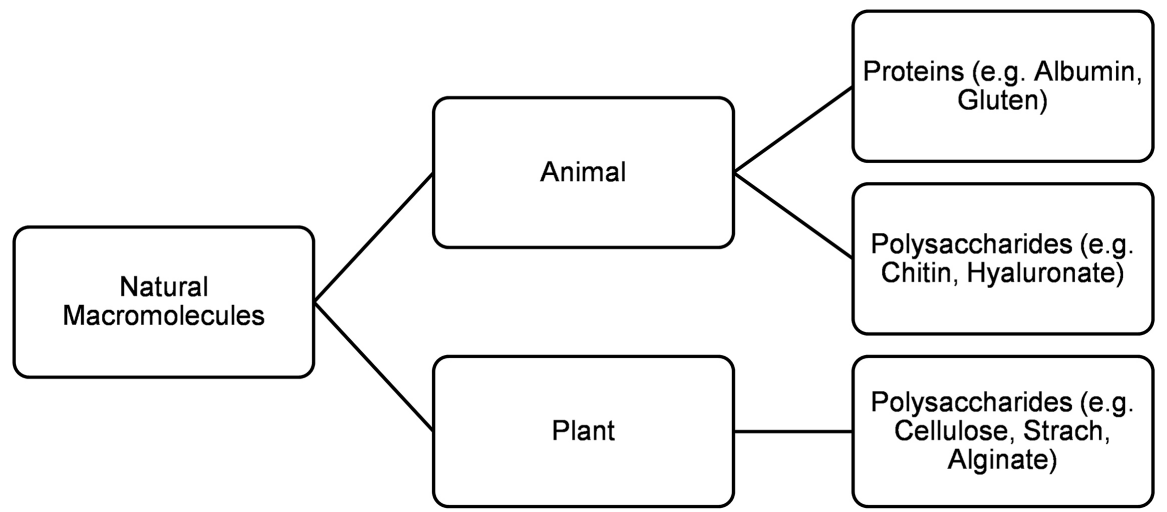

Figure 2. Classification of natural macromolecules.

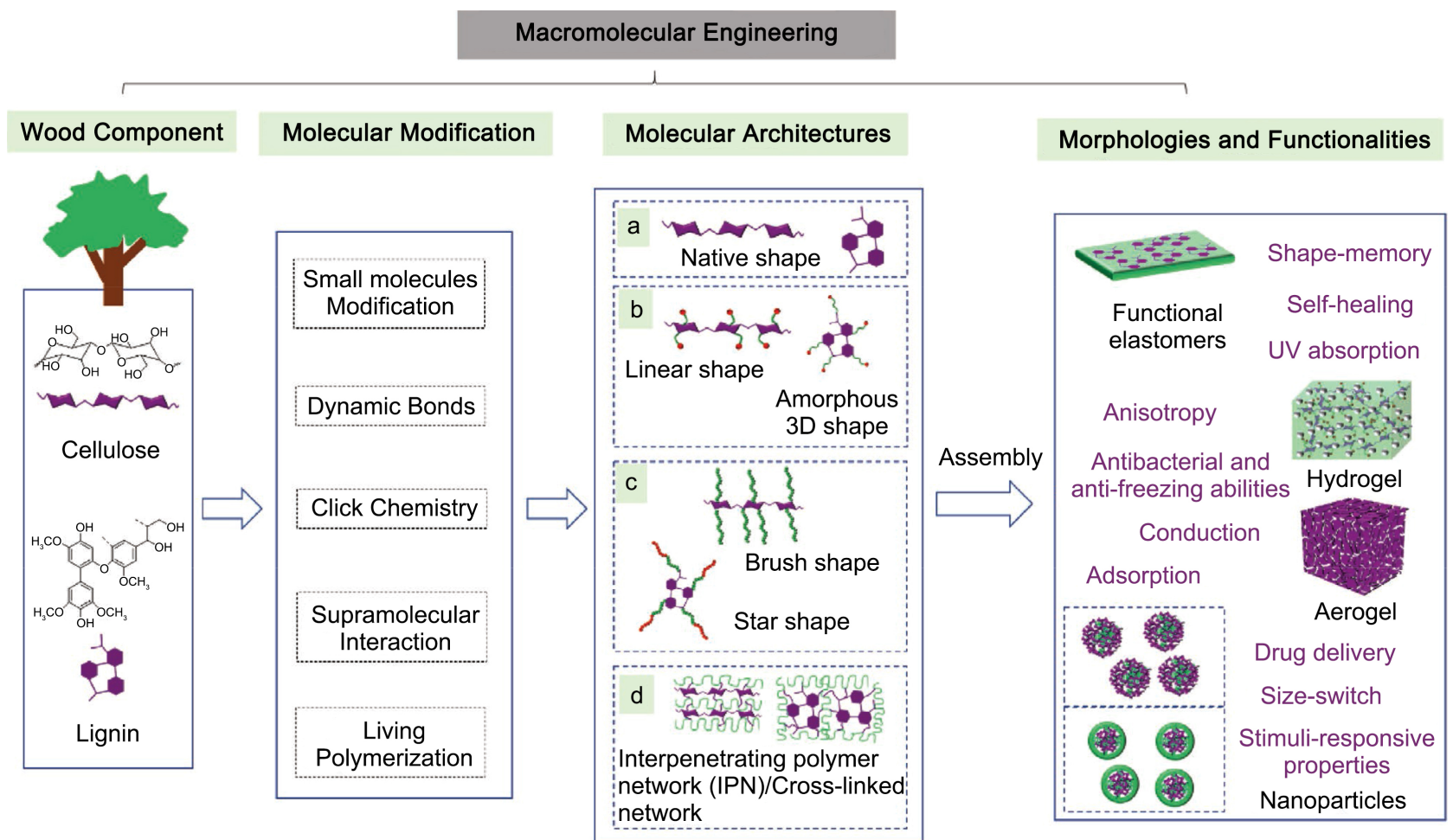

Figure 3. Macromolecular strategies for wood derivatives [23].

The use of wood macromolecules offers various opportunities for functionalization because of their unique structures and properties of cellulose \& lignin. As an example, the macromolecular have used in the functional polymeric materials such as elastomers, hydrogels, aerogels etc. From these, the fabrication process has applied in the elastomeric composite materials. Elastomer mainly as a natural or synthetic polymer which have the ability to recover their original shape after being stressed [24] [25]. It has widely used in the coatings, adhesives, fibers, footwear, medicals, leathers etc. [26] [27] [28]. Cellulose \& lignin from wood have been used for fabricate elastomers. From the view of a design principle for elastomer, the basic building blocks for elastomers comprise elastic and glassy components. In nature, the abundant hydroxyl groups in cellulose can form a 
physically cross-linked network by hydrogen bonding, which causes cellulose too rigid to be an elastomer. Similarly, lignin is also rigid enough and hardly used to directly prepare elastomers [29] [30] [31] [32]. The illustration is in Figure 4. Here, the cellulose-based ATRP macro initiators are synthesized by the esterification between the hydroxyl groups of cellulose \& 2-bromoisobutyryl bromide (Figure 4(a)). Then, by adding isoprene, it makes "Grafting form". Finally by cross-linked, the fabrication of elastomers are prepared (Figure 4(b)).

\subsection{Silk Based Fabrication of Composite Materials}

Silk is the animal based natural fiber, which consists of protein macromolecules [35] [36]. Silk fibers naturally produced by silkworms and spiders. By chemical modification or material morphologies silk proteins are collected from natural silkworms or spider silks [37] [38]. Different types of composite materials have prepared based on silk proteins [39] [40]. The fabrication of composite material in textiles, Bombyx mori silks have widely used due to their characteristics strength, moisture absorbance and luster [41] [42].

The silk proteins mixed with other polymers or particles for the preparation of composite materials. Firstly, the prepared composite based on silk proteins \& synthetic polymers are mixed together. Here, silk protein mixed with poly (acrylonitrile) for fabrication of composite materials. It observed that the improved of fibers water absorption and reduced their tendency to collect static electricity [43] [44]. Secondly, silk proteins mixed with biopolymer for the preparation of composite materials. Here, composite are made of cellulose \& silk fibroins [45]. Finally, preparation of antimicrobial composite, silk proteins mixed with silver nano particles. Here the fabrication done by the silver ions \& Bombyx mori coatings [46].

(a)
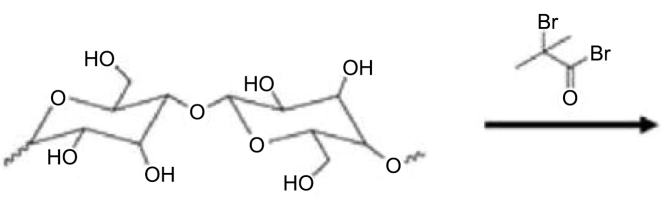

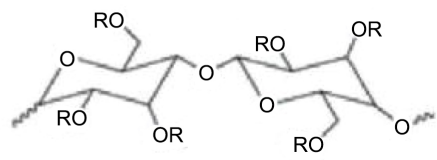

Cell-BiB

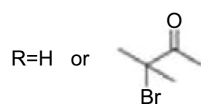

(b)

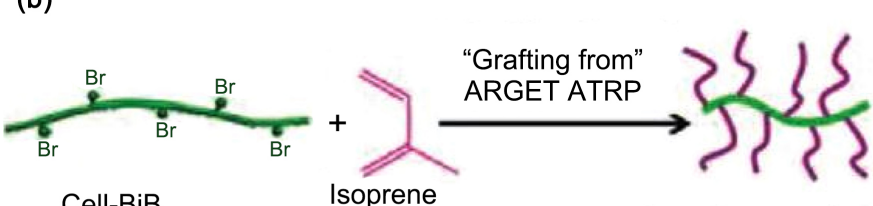

Cell-BiB Isoprene

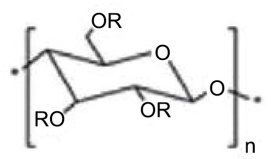

$\mathrm{R}=\mathrm{H}$ or $\underset{\mathrm{CH}_{3}}{\mathrm{CH}_{3}}$

Cell-g-PI

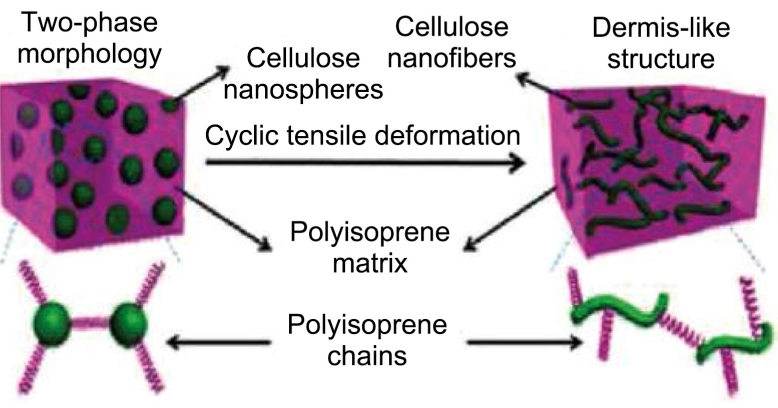

Figure 4. (a) Synthesis of cellulose-based ATRP macro initiator. (b) Fabrication of elastomers [33] [34]. 


\subsection{Wool Based Fabrication of Composite Materials}

Wool is one of animal based natural fiber which has good strength compared to other natural fiber. It also consists of protein macromolecules. Some of the studies examined that for the fabrication of composite material, macromolecules of wool shows excellent properties [1] [47]. Wool are collected from the skin of a sheep and fiber sizes \& shapes are varied from different species [48] [49].

Short wool fiber mixed with the polypropylene for the preparation of composite sheet. The fabrication was done by continuous extrusion. The composite shows good mechanical \& fire retardant properties [50] [51]. Mechanical behavior of wool macromolecules have shown in several studies with a good stand. For these reason, wool macromolecules are used in fabrication of composite materials in a large scale. Another studies for the fabrication of reinforced polyethylene composite, wool protein have used. By moulding process, protein (wool) and lignocellulose (nettle) natural fiber were prepared for the fabrication of low density polyethylene matrix. The composite showed excellent tensile \& flexural behaviors [52].

\section{Conclusion}

The exploitation of natural macromolecules in various applications has opened up new avenues for both researchers as well as industries to manufacture a sustainable module for future application in the fabrication of composite materials. Different types of natural macromolecules and their properties have been studied that it can be the potential replacement of synthetic macromolecules. The main concern of natural macromolecules is the environmental sustainability and ecological impact. The above discussion gives us a clear idea about some of the fabrication of composite materials which show excellent properties. That's why, the natural macromolecules should be the new application and opportunities for fabrication of composite materials in the $21^{\text {st }}$ century "green" materials environment.

\section{Conflicts of Interest}

The authors declare no conflicts of interest regarding the publication of this paper.

\section{References}

[1] Zhang, M.Q., Rong, M.Z. and Lu, X. (2005) Fully Biodegradable Natural Fiber Composites from Renewable Resources: All-Plant Fiber Composites. Composites Science and Technology, 65, 2514-2525.

https://doi.org/10.1016/j.compscitech.2005.06.018

[2] Pappu, A., Patil, V., Jain, S., Mahindrakar, A., Haque, R. and Thakur, V.K. (2015) Advances in Industrial Prospective of Cellulosic Macromolecules Enriched Banana Biofibre Resources: A Review. International Journal of Biological Macromolecules, 79, 449-458. https://doi.org/10.1016/j.ijbiomac.2015.05.013

[3] Gurunathan, T., Mohanty, S. and Nayak, S.K. (2015) A Review of the Recent De- 
velopments in Biocomposites Based on Natural Fibres and Their Application Perspectives. Composites Part A: Applied Science and Manufacturing, 77, 1-25. https://doi.org/10.1016/j.compositesa.2015.06.007

[4] Stevanovic, Z.D., Sieniawska, E., Glowniak, K., Obradovic, N. and Pajic-Lijakovic, I. (2020) Natural Macromolecules as Carriers for Essential Oils: From Extraction to Biomedical Application. Frontiers in Bioengineering and Biotechnology, 8, Article 563. https://doi.org/10.3389/fbioe.2020.00563

[5] Hopfinger, A. (2012) Conformational Properties of Macromolecules. Elsevier, Amsterdam.

[6] Tomalia, D.A., et al. (1985) A New Class of Polymers: Starburst-Dendritic Macromolecules. Polymer Journal, 17, 117-132. https://doi.org/10.1295/polymj.17.117

[7] Carson, M. (1987) Ribbon Models of Macromolecules. Journal of Molecular Graphics, 5, 103-106. https://doi.org/10.1016/0263-7855(87)80010-3

[8] Hecht, S. (2005) Construction with Macromolecules. Materials Today, 8, 48-55. https://doi.org/10.1016/S1369-7021(05)00747-9

[9] Bernal, J. (1958) General Introduction Structure Arrangements of Macromolecules. Discussions of the Faraday Society, 25, 7-18. https://doi.org/10.1039/df9582500007

[10] Sun, S. (1994) Physical Chemistry of Macromolecules. John Willey and Sons Inc., New York.

[11] Yousif, B. and El-Tayeb, N. (2007) Tribological Evaluations of Polyester Composites Considering Three Orientations of CSM Glass Fibres Using BOR Machine. Applied Composite Materials, 14, 105-116. https://doi.org/10.1007/s10443-007-9034-2

[12] Mia, R., Selim, M., Shamim, A., Chowdhury, M. and Sultana, S. (2019) Review on Various Types of Pollution Problem in Textile Dyeing \& Printing Industries of Bangladesh and Recommandation for Mitigation. Journal of Textile Engineering \& Fashion Technology, 5, 220-226. https://doi.org/10.15406/jteft.2019.05.00205

[13] Okolie, C.L., Akanbi, T.O., Mason, B., Udenigwe, C.C. and Aryee, A.N. (2019) Influence of Conventional and Recent Extraction Technologies on Physicochemical Properties of Bioactive Macromolecules from Natural Sources: A Review. Food Research International, 116, 827-839. https://doi.org/10.1016/j.foodres.2018.09.018

[14] Hieke, A. (2011) Methods and Apparatus for Ion Sources, Ion Control and Ion Measurement for Macromolecules. Google Patents.

[15] Chandramohan, D. and Marimuthu, K. (2011) A Review on Natural Fibers. International Journal of Research and Reviews in Applied Sciences, 8, 194-206.

[16] Kicińska-Jakubowska, A., Bogacz, E. and Zimniewska, M. (2012) Review of Natural Fibers. Part I-Vegetable Fibers. Journal of Natural Fibers, 9, 150-167. https://doi.org/10.1080/15440478.2012.703370

[17] M. Sajib, B. Banna, and R. Mia, (2020) Mosquito Repellent Finishes on Textile Fabrics (Woven \& Knit) by Using Different Medicinal Natural Plants. Journal of Textile Engineering \& Fashion Technology, 6, 164-167.

[18] Anderson, J.W. and Chen, W.L. (1979) Plant Fiber. Carbohydrate and Lipid Metabolism. The American Journal of Clinical Nutrition, 32, 346-363. https://doi.org/10.1093/ajcn/32.2.346

[19] Han, J.S. (1998) Properties of Nonwood Fibers. In: Proceedings of the Korean Society of Wood Science and Technology Annual Meeting, The Korean Society of Science and Technology, Seoul, 3-12.

[20] Englyst, H.N. and Kingman, S.M. (1990) Dietary Fiber and Resistant Starch. In: Dietary Fiber, Springer, Berlin, 49-65. https://doi.org/10.1007/978-1-4613-0519-4_4 
[21] Azwa, Z., Yousif, B., Manalo, A. and Karunasena, W. (2013) A Review on the Degradability of Polymeric Composites Based on Natural Fibres. Materials \& Design, 47, 424-442. https://doi.org/10.1016/j.matdes.2012.11.025

[22] Satyanarayana, K.G., Arizaga, G.G. and Wypych, F. (2009) Biodegradable Composites Based on Lignocellulosic Fibers-An Overview. Progress in Polymer Science, 34, 982-1021. https://doi.org/10.1016/j.progpolymsci.2008.12.002

[23] Wang, J., Zhang, D. and Chu, F. (2020) Wood-Derived Functional Polymeric Materials. Advanced Materials, Article ID: 2001135.

https://doi.org/10.1002/adma.202001135

[24] Christensen, R. (1980) A Nonlinear Theory of Viscoelasticity for Application to Elastomers. Journal of Applied Mechanics, 47, 762-768. https://doi.org/10.1115/1.3153787

[25] Voda, M., Demco, D., Perlo, J., Orza, R. and Blümich, B. (2005) Multispin Moments Edited by Multiple-Quantum NMR: Application to Elastomers. Journal of Magnetic Resonance, 172, 98-109. https://doi.org/10.1016/j.jmr.2004.10.001

[26] Puskas, J.E. and Chen, Y. (2004) Biomedical Application of Commercial Polymers and Novel Polyisobutylene-Based Thermoplastic Elastomers for Soft Tissue Replacement. Biomacromolecules, 5, 1141-1154. https://doi.org/10.1021/bm034513k

[27] Haly, A. and Feughelman, M. (1957) Application of Statistical Theory of Elastomers to Supercontracted Keratin Fibers. Textile Research Journal, 27, 919-924. https://doi.org/10.1177/004051755702701201

[28] Gary, J.J. and Smith, C.T. (1998) Pigments and Their Application in Maxillofacial Elastomers: A Literature Review. The Journal of Prosthetic Dentistry, 80, 204-208. https://doi.org/10.1016/S0022-3913(98)70111-8

[29] Liu, Y., et al. (2014) Sustainable Thermoplastic Elastomers Derived from Renewable Cellulose, Rosin and Fatty Acids. Polymer Chemistry, 5, 3170-3181. https://doi.org/10.1039/c3py01260c

[30] Jiang, F., Wang, Z., Qiao, Y., Wang, Z. and Tang, C. (2013) A Novel Architecture toward Third-Generation Thermoplastic Elastomers by a Grafting Strategy. Macromolecules, 46, 4772-4780. https://doi.org/10.1021/ma4007472

[31] Yu, J., Lu, C., Wang, C., Wang, J., Fan, Y. and Chu, F. (2017) Sustainable Thermoplastic Elastomers Derived from Cellulose, Fatty Acid and Furfural via ATRP and Click Chemistry. Carbohydrate Polymers, 176, 83-90. https://doi.org/10.1016/j.carbpol.2017.08.060

[32] Kim, J., Yun, S. and Ounaies, Z. (2006) Discovery of Cellulose as a Smart Material. Macromolecules, 39, 4202-4206. https://doi.org/10.1021/ma060261e

[33] Wang, Z., Jiang, F., Zhang, Y., You, Y., Wang, Z. and Guan, Z. (2015) Bioinspired Design of Nanostructured Elastomers with Cross-Linked Soft Matrix Grafting on the Oriented Rigid Nanofibers to Mimic Mechanical Properties of Human Skin. ACS Nano, 9, 271-278. https://doi.org/10.1021/nn506960f

[34] Wang, Z., Zhang, Y., Jiang, F., Fang, H. and Wang, Z. (2014) Synthesis and Characterization of Designed Cellulose-Graft-Polyisoprene Copolymers. Polymer Chemistry, 5, 3379-3388. https://doi.org/10.1039/c3py01574b

[35] Kato, N., Sato, S., Yamanaka, A., Yamada, H., Fuwa, N. and Nomura, M. (1998) Silk Protein, Sericin, Inhibits Lipid Peroxidation and Tyrosinase Activity. Bioscience, Biotechnology, and Biochemistry, 62, 145-147. https://doi.org/10.1271/bbb.62.145

[36] Zhang, Y.-Q. (2002) Applications of Natural Silk Protein Sericin in Biomaterials. Biotechnology Advances, 20, 91-100. https://doi.org/10.1016/S0734-9750(02)00003-4 
[37] Arai, T., Freddi, G., Innocenti, R., Kaplan, D. and Tsukada, M. (2001) Acylation of Silk and Wool with Acid Anhydrides and Preparation of Water-Repellent Fibers. Journal of Applied Polymer Science, 82, 2832-2841. https://doi.org/10.1002/app.2137

[38] Arai, T., Freddi, G., Innocenti, R. and Tsukada, M. (2003) Preparation of Water-Repellent Silks by a Reaction with Octadecenylsuccinic Anhydride. Journal of Applied Polymer Science, 89, 324-332. https://doi.org/10.1002/app.12081

[39] Hardy, J.G. and Scheibel, T.R. (2010) Composite Materials Based on Silk Proteins. Progress in Polymer Science, 35, 1093-1115. https://doi.org/10.1016/j.progpolymsci.2010.04.005

[40] Sutherland, T.D., Young, J.H., Weisman, S., Hayashi, C.Y. and Merritt, D.J. (2010) Insect Silk: One Name, Many Materials. Annual Review of Entomology, 55, 171-188. https://doi.org/10.1146/annurev-ento-112408-085401

[41] Prachayawarakorn, J. and Boonsawat, K. (2007) Physical, Chemical, and Dyeing Properties of Bombyx mori Silks Grafted by 2-Hydroxyethyl Methacrylate and Methyl Methacrylate. Journal of Applied Polymer Science, 106, 1526-1534. https://doi.org/10.1002/app.26586

[42] Prachayawarakorn, J. and Khanchaiyapoom, K. (2010) Dyeing Properties of Bombyx mori Silks Grafted by 2-Hydroxyethyl Methacrylate (HEMA). Fibers and Polymers, 11, 1010-1017. https://doi.org/10.1007/s12221-010-1010-Z

[43] Cates, D.M. and White Jr., H.J. (1956) Preparation and Properties of Fibers Containing Mixed Polymers. III. Polyacrylonitrile-Silk Fibers. Journal of Polymer Science, 21, 125-138. https://doi.org/10.1002/pol.1956.120219711

[44] Sun, Y., Shao, Z., Ma, M., Hu, P., Liu, Y. and Yu, T. (1997) Acrylic Polymer-Silk Fibroin Blend Fibers. Journal of Applied Polymer Science, 65, 959-966. https://doi.org/10.1002/(SICI)1097-4628(19970801)65:5<959::AID-APP14>3.0.CO; $\underline{2-\mathrm{N}}$

[45] Marsano, E., Canetti, M., Conio, G., Corsini, P. and Freddi, G. (2007) Fibers Based on Cellulose-Silk Fibroin Blend. Journal of Applied Polymer Science, 104, 2187-2196. https://doi.org/10.1002/app.24856

[46] Gulrajani, M., Gupta, D., Periyasamy, S. and Muthu, S. (2008) Preparation and Application of Silver Nanoparticles on Silk for Imparting Antimicrobial Properties. Journal of Applied Polymer Science, 108, 614-623. https://doi.org/10.1002/app.27584

[47] Tu, H., et al. (2016) Programing Performance of Wool Keratin and Silk Fibroin Composite Materials by Mesoscopic Molecular Network Reconstruction. Advanced Functional Materials, 26, 9032-9043. https://doi.org/10.1002/adfm.201603403

[48] Novotny, E.H. and Hedges, L.M. (1955) Method and Apparatus for Fiber Collection. Google Patents.

[49] Parsons, J.R. (1941) Apparatus for Producing Mineral Wool. Google Patents.

[50] Mia, R., Islam, M.A., Ahmed, B. and Mojumdar, J.I.A. (2017) Woolenization of Jute Fibre. European Scientific Journal, 13, 314-326.

https://doi.org/10.19044/esj.2017.v13n30p314

[51] Kim, N., Lin, R. and Bhattacharyya, D. (2014) Extruded Short Wool Fibre Composites: Mechanical and Fire Retardant Properties. Composites Part B: Engineering, 67, 472-480. https://doi.org/10.1016/j.compositesb.2014.08.002

[52] Yallew, T.B., Kumar, P. and Singh, I. (2016) Mechanical Behavior of Nettle/Wool Fabric Reinforced Polyethylene Composites. Journal of Natural Fibers, 13, 610-618. https://doi.org/10.1080/15440478.2015.1093576 